\title{
Association between anthropometry- based nutritional status and malaria: a systematic review of observational studies
}

\author{
Efrem d'Avila Ferreira ${ }^{1,2}$, Márcia A. Alexandre ${ }^{1,2}$, Jorge L. Salinas ${ }^{3}$, André M. de Siqueira ${ }^{1,2,4}$, Silvana G. Benzecry², \\ Marcus V. G. de Lacerda ${ }^{1,2,5}$ and Wuelton M. Monteiro ${ }^{1,2^{*}}$
}

\begin{abstract}
Background: Multiple studies in various parts of the world have analysed the association of nutritional status on malaria using anthropometric measures, but results differ due to the heterogeneity of the study population, species of the parasite, and other factors involved in the host and parasite relationship. The aim of this study was to perform a systematic review on the inter-relationship of nutritional status based on anthropometry and malarial infection.

Methods: Two independent reviewers accessed the MEDLINE and LILACS databases using the same search terms related to malaria and anthropometry. Prospective studies associating anthropometry and malaria (incidence or severity) were selected. References from the included studies and reviews were used to increase the review sensitivity. Data were extracted using a standardized form and the quality of the prospective studies was assessed. Selected articles were grouped based on exposures and outcomes.

Results: The search identified a total of 1688 studies: 1629 from MEDLINE and 59 from LILACS. A total of 23 met the inclusion criteria. Five additional studies were detected by reading the references of the 23 included studies and reviews, totaling 28 studies included. The mean sample size was 662.1 people, ranging from 57 to 5620 . The mean follow-up was 365.8 days, ranging from 14 days to 1 year and 9 months, and nine studies did not report the follow-up period. Prospective studies assessing the relationship between malaria and malnutrition were mostly carried out in Africa. Of the 20 studies with malarial outcomes, fifteen had high and five had average quality, with an average score of $80.5 \%$. Most anthropometric parameters had no association with malaria incidence $(47 / 52 ; 90.4 \%)$ or parasite density (20/25; $80 \%)$. However, the impact of malnutrition was noted in malaria mortality and severity (7/17; 41.2\%). Regarding the effects of malaria on malnutrition, malaria was associated with very few anthropometric parameters (8/39; 20.6\%).

Conclusions: This systematic review found that most of the evidence associating malaria and malnutrition comes from $P$. falciparum endemic areas, with a significant heterogeneity in studies' design. Apparently malnutrition has not a great impact on malaria morbidity, but could have a negative impact on malaria mortality and severity. Most studies show no association between malaria and subsequent malnutrition in P. falciparum areas. In Plasmodium vivax endemic areas, malaria was associated with malnutrition in children. A discussion among experts in the field is needed to standardize future studies to increase external validity and accuracy.
\end{abstract}

Keywords: Malaria, Plasmodium vivax, Plasmodium falciparum, Malnutrition, Anthropometry, Cohort studies

\footnotetext{
*Correspondence: wueltonmm@gmail.com

${ }^{2}$ Universidade do Estado do Amazonas, Av. Pedro Teixeira, 25, Dom Pedro,

Manaus, AM 69040-000, Brazil

Full list of author information is available at the end of the article
} 


\section{Background}

Nutritional status is a closely tied to immune responses to infection, being on the one hand, an important determinant of the risk and prognosis of infectious diseases, and on the other hand, being directly influenced by infection [1]. This bi-directional pattern of synergistic interaction in which, a worse nutritional status negatively contributes to the development and evolution of infections, whereas infections lead to a worsening of nutritional status, is a crucial phenomenon for the understanding of infections' population dynamics and to establish control strategies for these diseases $[2,3]$.

Malaria is a preventable, diagnosable and treatable disease. With recent innovations and roll out of multinational interventions, there are fewer people dying from malaria today than 10 years ago. Nonetheless, malaria is still a deadly disease with approximately 219 million cases and 660,000 deaths in 2013 [4]. Malnutrition is also a major public health problem in tropical areas where malaria prevails, with estimated $38 \%$ stunted, $28 \%$ underweight, and $9 \%$ wasted in Africa [5]. To date, findings from studies evaluating associations between various measures of malnutrition and malaria have been contradictory.

Nutritional status impacts on mortality among children under 5 years due to diarrhoea, respiratory diseases, malaria and measles [6]. In relation to morbidity, a big part of the studies found that children and adolescents with chronic malnutrition (stunting) and low weight for age (underweight) besides thin adult have protection against prevalent cerebral malaria [7-10], stunted and underweight children and adolescents have less prevalence and incidence of hyperparasitaemia [11-16] and, to a lower extent, children and adolescents with wasting or stunting were protected against new episodes of clinical malaria $[17,18]$. Although limited by the small number of studies, malnutrition may contribute to deaths from malaria, even though the significance was not high compared with other diseases [2, 7, 18-20]. In contrast, some studies found no association between nutrition and subsequent mortality from malaria $[21,22]$.

Although several studies in various parts of the world analysed the impact of nutritional status on malaria using anthropometric measures, their results differ due to the heterogeneity of the study population, species of the parasite, and other factors involved in host and parasite relationship. The aim of this study was to perform a systematic review on the evidence for relationship between malaria and subsequent chronic or acute malnutrition based on anthropometry, for the protective effect of malnutrition on malaria outcomes, and for malnutrition increasing the risk of adverse malaria outcomes.

\section{Methods}

\section{Search strategy}

A systematic review was performed in order to identify the available published data on malaria and malnutrition causal interactions. A broad free text search was made using the terms (malaria OR plasmodium) AND [(anthropometry) OR (anthropometric) OR (nutrition)) for PUBMED and (malaria OR plasmodium) AND (anthropometry) OR (anthropometric) OR (nutri\$)] for LILACS. Potentially relevant papers in all languages were accessed from MEDLINE (September 2014) and LILACS (September 2014) in order to review full texts. Additional articles were obtained through citation tracking of reviews/opinion articles and original papers. The titles, abstracts, and studies identified in the literature search were assessed by two reviewers. All studies matching the inclusion criteria were reviewed by the authors and disagreement in conclusion was settled through discussion. Articles written in English, Portuguese, Spanish, German and French were included.

\section{Inclusion criteria, exposures and outcomes}

For this study, observational studies in non-pregnant populations and without co-morbidities (co-infections, genetic or metabolic and other chronic diseases) were included. Studies on any of the Plasmodium species were included. Only original prospective cohort studies were included, presenting one of the following characteristics of exposure and outcome:

1. Malnutrition assessed by anthropometric measurements as the independent variable and morbidity or mortality from malaria as the outcome.

2. Malaria as an exposure variable and malnutrition assessed by anthropometric measurements as the outcome.

The anthropometric variables gathered in the articles were anthropometric indices [(height/age (H/A), weight/height $(\mathrm{W} / \mathrm{H})$, weight/age $(\mathrm{W} / \mathrm{A})$, arm circumference/age $(\mathrm{AC} / \mathrm{A})$, body mass index (BMI)], measures of skinfold thicknesses, body circumferences and increments in weight, height or anthropometric measures throughout follow-up. As malarial variables, we looked for frequencies of malaria such as incidence or prevalence, parasitaemia, complications and mortality as outcomes. Severity criteria recommended by the World Health Organization (anaemia, cerebral malaria, hypoglycaemia, renal failure, pulmonary oedema, or acute respiratory distress syndrome, circulatory collapse, abnormal bleeding or disseminated intravascular coagulation, haemoglobinuria, seizures, acidosis, hyperbilirubinaemia, hyperpyrexia and prostration) were used [23]. 


\section{Data extraction}

One independent reviewer (EDF) supervised by a senior reviewer (MAA) extracted the relevant data using a predesigned data extraction form. Disagreements between the two reviewers were resolved by referring to a third reviewer (WMM). Information for article identification, exposure variables and outcome measurement, sample size, age group, level of malaria transmission in the study site, follow-up time, species of Plasmodium spp., confounders adjusted in the analysis and type of association were extracted. Data on the type of association (statistical comparison) between the exposure and the outcome were retrieved. The association was classified as neutral when the exposure had no impact on the outcome, as risk when the exposure increased the outcome and as protection when the exposure decreased the outcome.

\section{Evidence quality evaluation}

To assess the quality of the included studies, an adapted questionnaire originated from the Check List for Measuring Quality proposed by Downs and Black was applied [24]. The validity of the studies was determined by scores received after the evaluation of 12 questions, according to Table 1. For each question with an affirmative answer, 1 point was assigned to the study. Negative or inconclusive responses did not lead to scoring. Studies with scores $>70 \%$ were considered of high quality, while studies with scores 50-69.9\% were considered of intermediate quality score and below $50 \%$ classified as low quality.

\section{Results}

Selection and general characteristics of the study

The search identified a total of 1688 studies: 1629 from MEDLINE and 59 from LILACS. After screening titles and abstracts, 950 publications were excluded due to a lack of information regarding an association between malaria and malnutrition, not being original articles or being duplicates, reviews, reports, case-control, ecological or cross-sectional studies, unavailable articles and presence of co-morbidities in participants (Fig. 1). After reading the remaining 738 full articles, 598 more publications were excluded for similar reasons. A total of 139 studies were taken to a consensus meeting, where 116 did not meet the inclusion criteria. References of the 23 included articles were reviewed, giving 5 extra articles, totaling 28 items for systematic review published from 1977 to 2014.

Twenty-three $(82.1 \%)$ studies were conducted in Africa, three $(10.7 \%)$ in Oceania (two of Papua New Guinea and Vanuatu), one (3.5\%) in Asia (Vietnam) and one $(3.5 \%)$ in South-America (Brazil). African countries with the largest number of studies were Gambia (4), Congo (3) and Ghana (3). Of the 28 included studies, one was done in the $70 \mathrm{~s}$, one in the $80 \mathrm{~s}$, ten in the $90 \mathrm{~s}$, nine in the 2000s and seven in the decade of 2010. Among the 28 included studies, 20 presented anthropometric variables as exposure and had malaria as the outcome, while 13 had malaria as the exposure and malnutrition as the outcome. Five studies conducted evaluations in both directions and were included in both analyses.

Eleven studies did not report the agent responsible for malaria, all from Africa where P. falciparum prevails. Fourteen studies had participants with falciparum malaria, one with falciparum and vivax, one with falciparum, malariae and vivax and one with vivax/falciparum malaria. The setting was characterized as hyperendemic in nine studies, as holoendemic in two, endemic in four, hypoendemic in two, mesoendemic in one and endemicity was not reported in 10 studies. The mean sample size was 662.1 people, ranging from 57 to 5620 . The mean

Table 1 Questions used for evidence quality evaluation in the systematic review

\begin{tabular}{|c|c|}
\hline Order & Question \\
\hline 1 & The study clearly describes its objectives and hypotheses? \\
\hline 2 & The study clearly describes the exposures and outcomes? \\
\hline 3 & The study describes basic characteristics of participants (age and gender)? \\
\hline 4 & The results of the statistical analysis were presented explicitly ( $p$ values and/or confidence intervals)? \\
\hline 5 & $\begin{array}{l}\text { The study provided estimates of random variability in the results of the main outcome measures (standard deviation, standard error, confi- } \\
\text { dence interval)? }\end{array}$ \\
\hline 6 & The results were adjusted for possible confounding variables through stratification or multivariate analysis? \\
\hline 7 & The study informs the loss characteristics (numbers and reasons)? \\
\hline 8 & Participants were followed for the same time or the study was adjusted for different follow-up times? \\
\hline 9 & Statistical tests used were adequate (non application of parametric statistics for population under 100)? \\
\hline 10 & The measures used for the main outcomes were accurate (description of the technique for the diagnosis of malaria and nutritional status)? \\
\hline 11 & The demographic characteristics of the groups were comparable or adjusted (age and geographic area)? \\
\hline 12 & The participants of different groups were recruited in the same period of time? \\
\hline
\end{tabular}




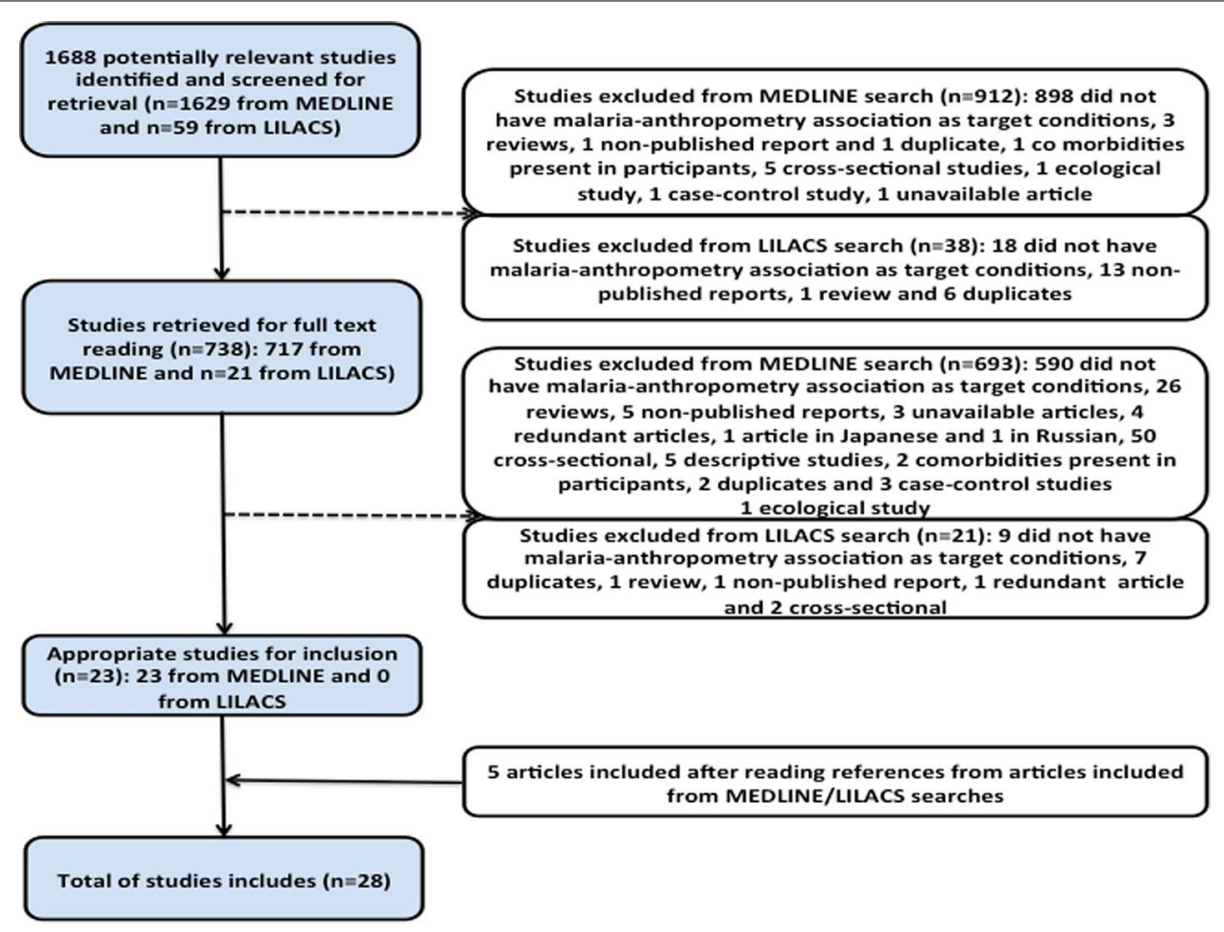

Fig. 1 Flow chart of study selection

follow-up was 365.8 days, ranging from 14 days to 1 year and 9 months, and nine studies did not report the followup period. The characteristics and results of these studies are shown in Tables 2 and 3.

\section{Malnutrition as exposure for malaria}

Twenty studies with malaria-related outcomes were included, twelve evaluating incidence, seven mortality and six parasitaemia. Five studies evaluated more than one type of outcome.

\section{Anthropometric parameters}

The most assessed anthropometric measures were W/A, with 25 evaluations from 14 studies, and H/A, with 27 evaluations from 11 studies. The $\mathrm{W} / \mathrm{H}$ measure was obtained in 24 evaluations from 10 studies. The measure AC/A was obtained in four evaluations from two studies. All the other measures (AC, weight increment, W/A increment, H/A increment, W/A increment, $\mathrm{AC} / \mathrm{A}$ increment and a combined index from $\mathrm{H} / \mathrm{A}+\mathrm{L} / \mathrm{A}+\mathrm{W} / \mathrm{H}+\mathrm{W} / \mathrm{A}$ measures) were obtained in two evaluations from one study each. Thus, a total of 92 different anthropometric measures were obtained from the 20 studies, being 14 using National Center Health Statistics 1977 [25], four the World Health Organization 2006 (WHO 2006) [26] and one the WHO 2007 [27] as standards. One study used weight increment (Fig. 2).

\section{Malaria incidence}

The impact of malnutrition on malaria incidence was assessed in 50 statistical comparisons from 12 studies, on parasite density in 25 comparisons from six studies and on mortality in 17 comparisons from seven studies (Table 2). Of the 50 comparisons between malnutrition and malaria incidence, 37 evaluated clinical malaria in general, four evaluated specifically asymptomatic malaria, four evaluated Plasmodium falciparum malaria, two evaluated Plasmodium vivax malaria, two evaluated Plasmodium malariae malaria and one evaluated specifically non-severe malaria. Most of the evaluations failed to show any association between malnutrition and malaria incidence; 45/50 (90 \%). However, three evaluations showed a risk association between malnutrition and malaria incidence in children: (1) underweight on $P$. vivax incidence in children above 10 years with undisclosed follow-up time [30]; (2) AC/A on P. falciparum incidence in children under 9 months years with 3 months of follow-up [32]; (3) Stunting on $P$. falciparum incidence in children between 0 and 5 years with 20 weeks of follow-up [33]. Two evaluations showed a protective association: (1) Stunting on malaria incidence in children between 12 and 70 months with 25 weeks of follow-up [17]; (2) stunting on $P$. vivax incidence in children up to 14 years with 1 year of follow-up [38]. 


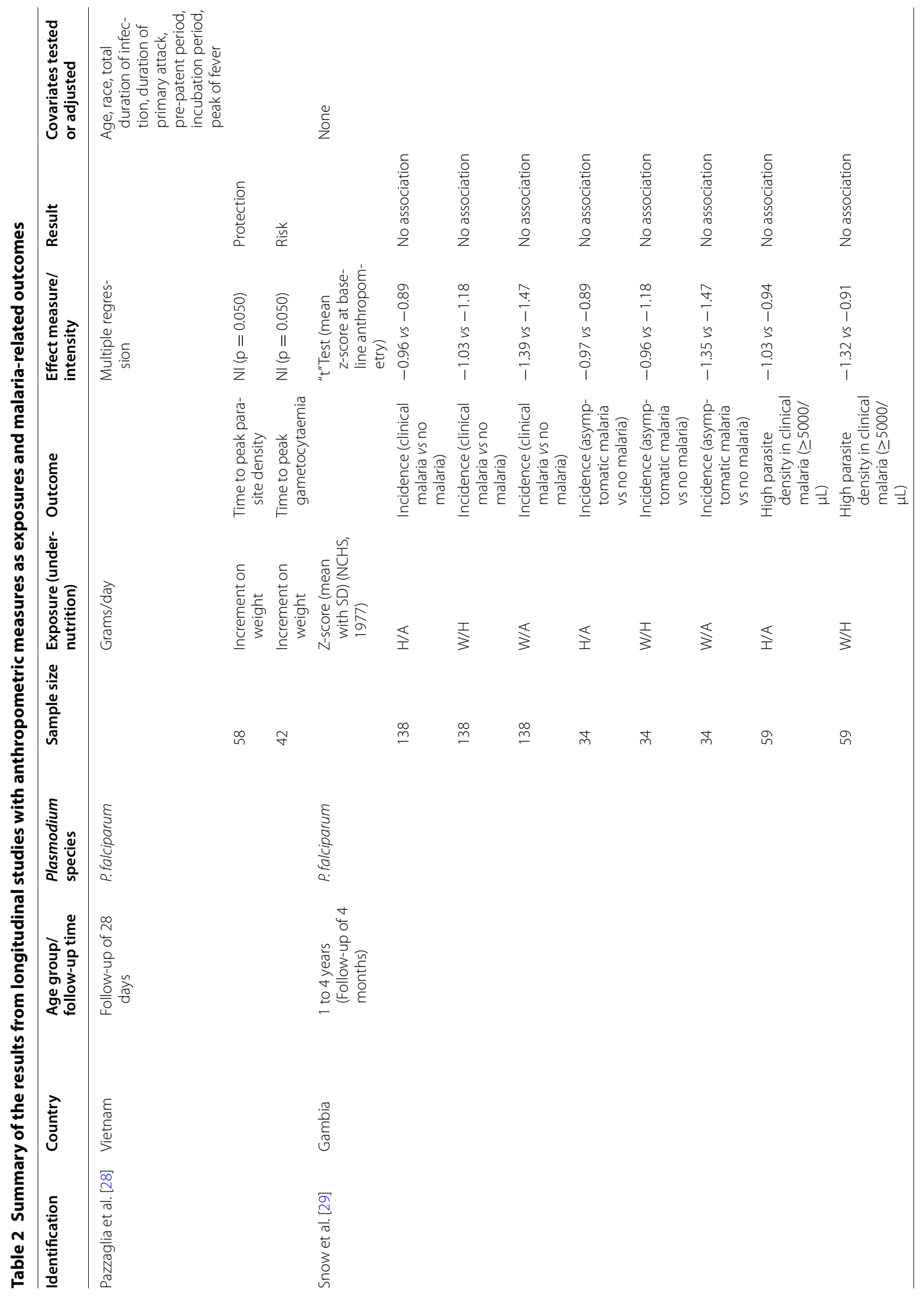




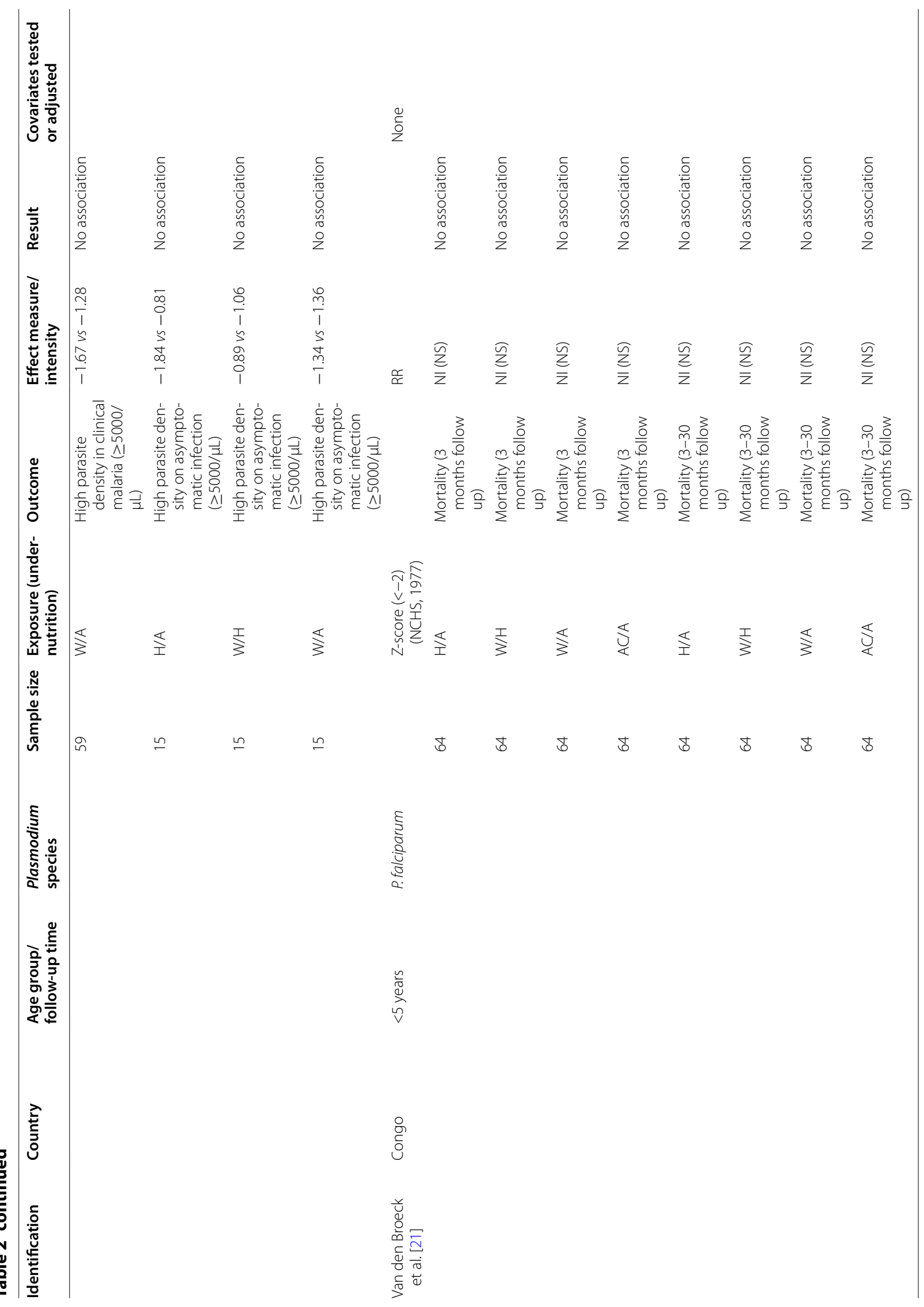




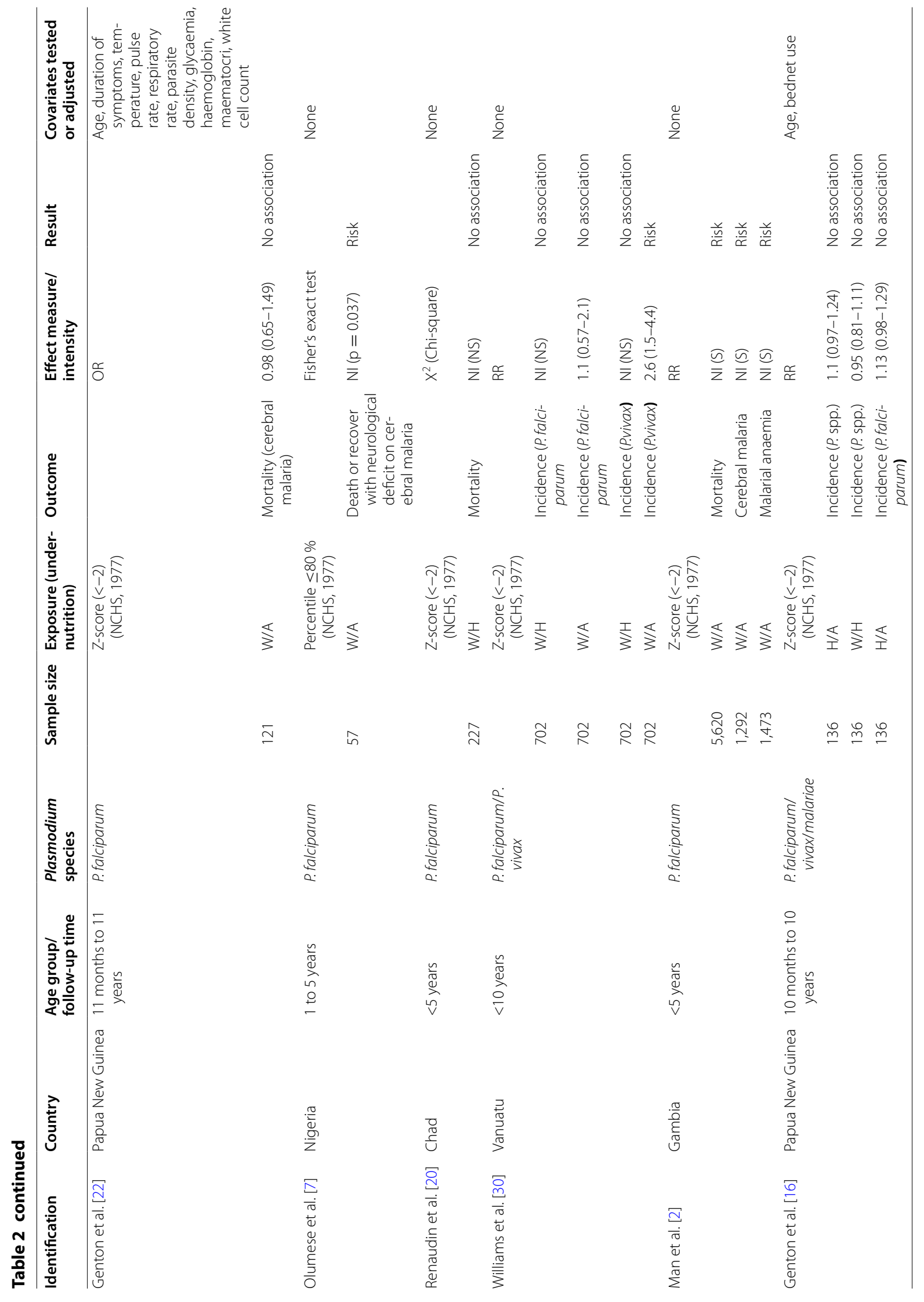




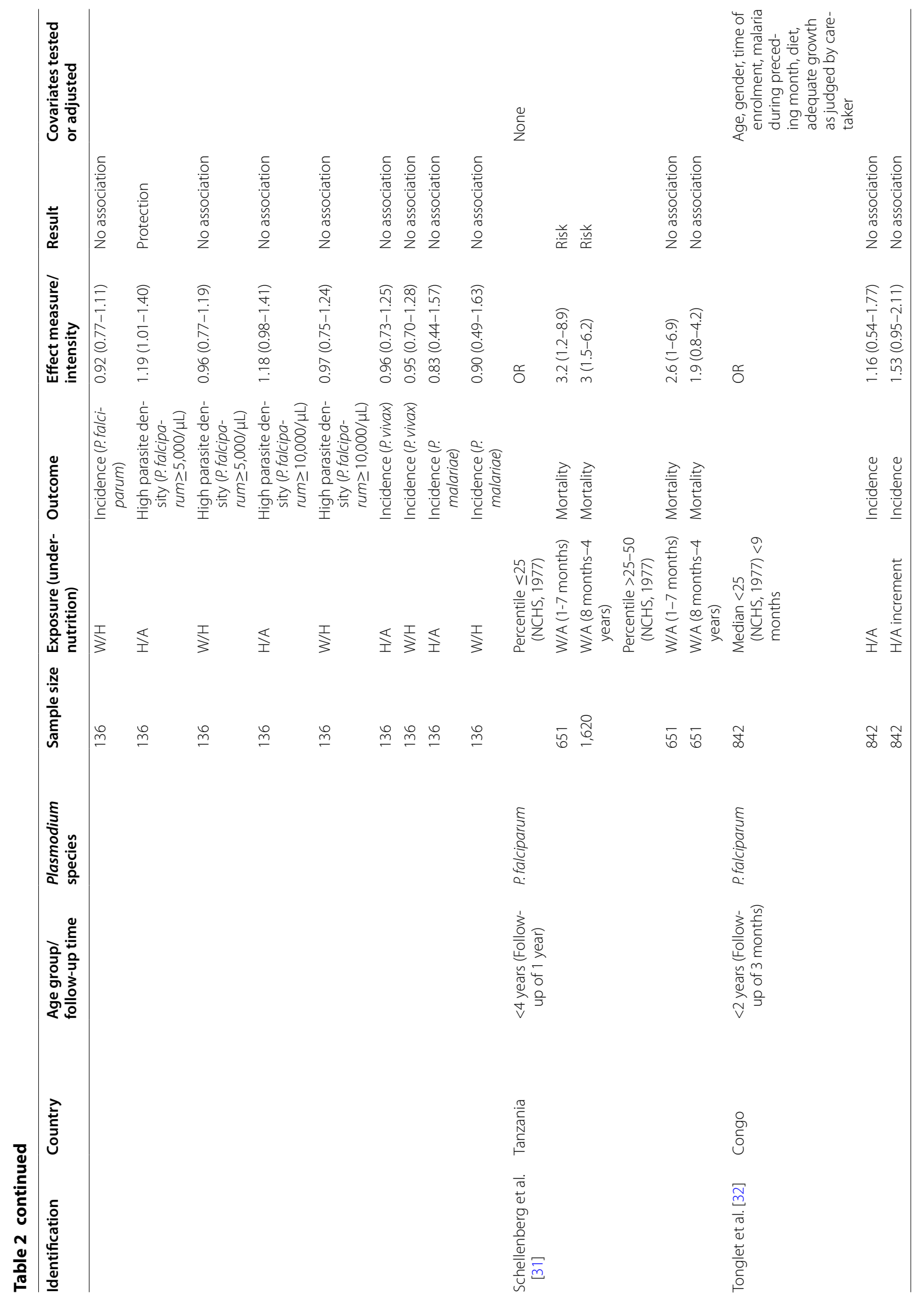




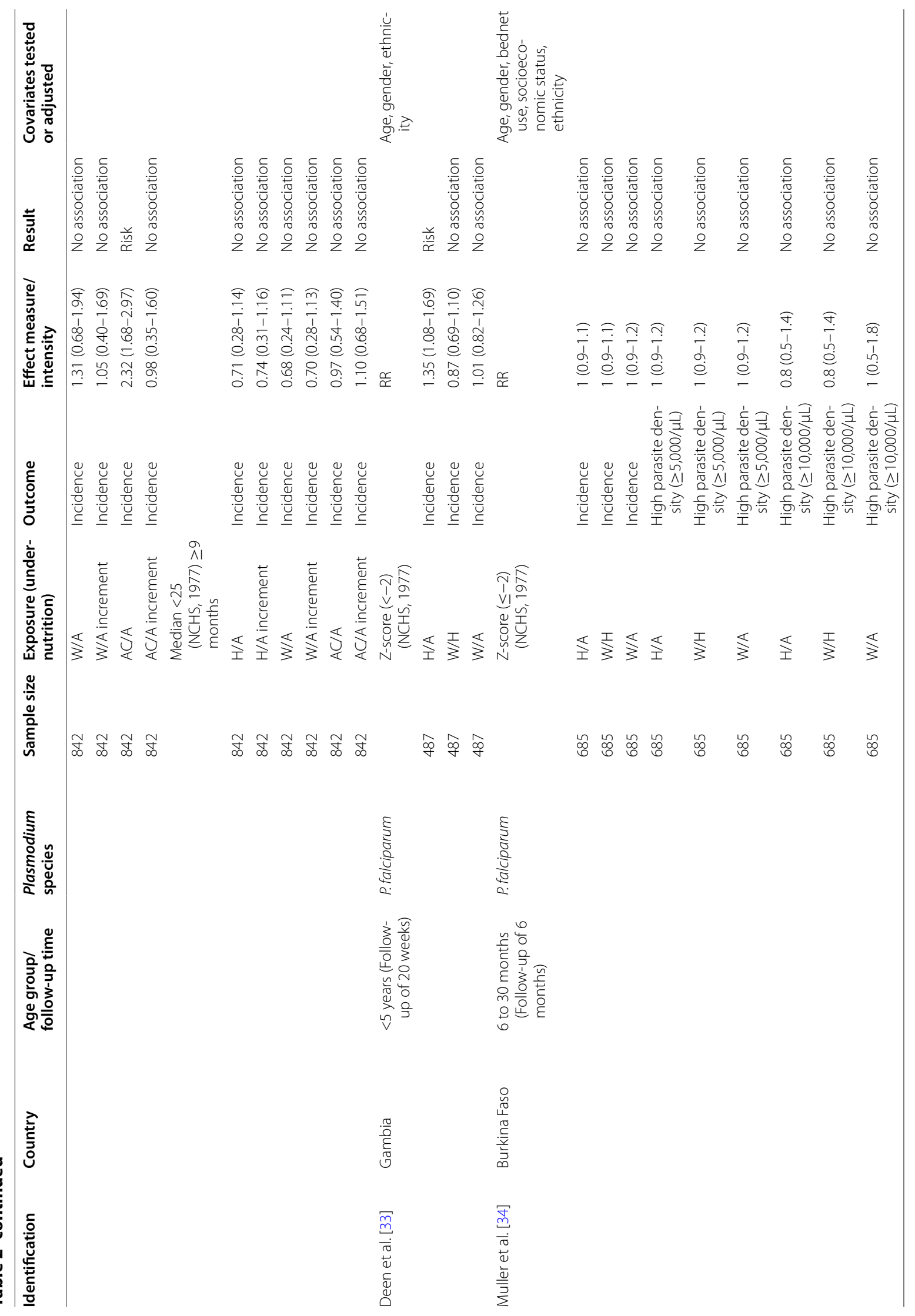




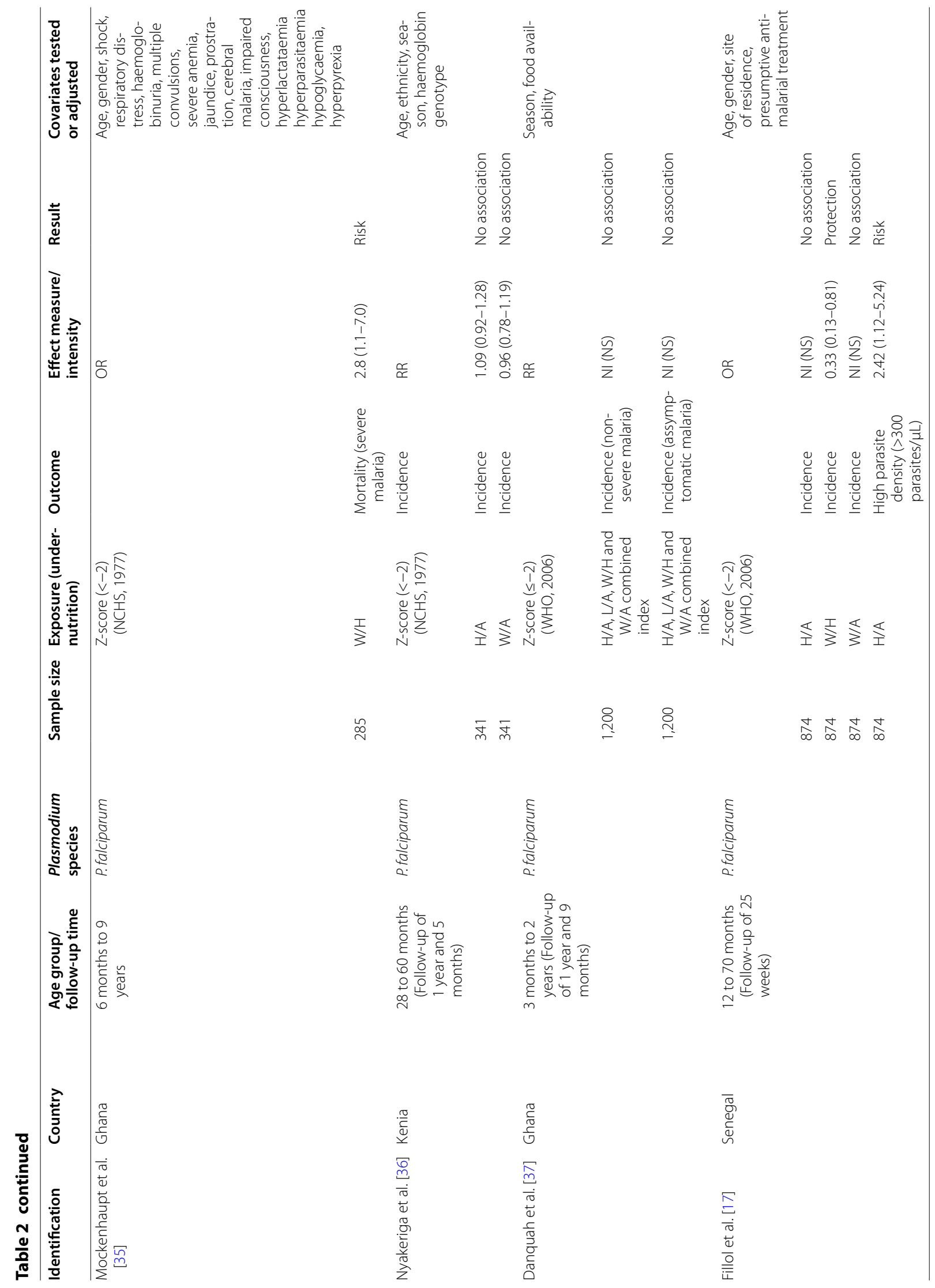




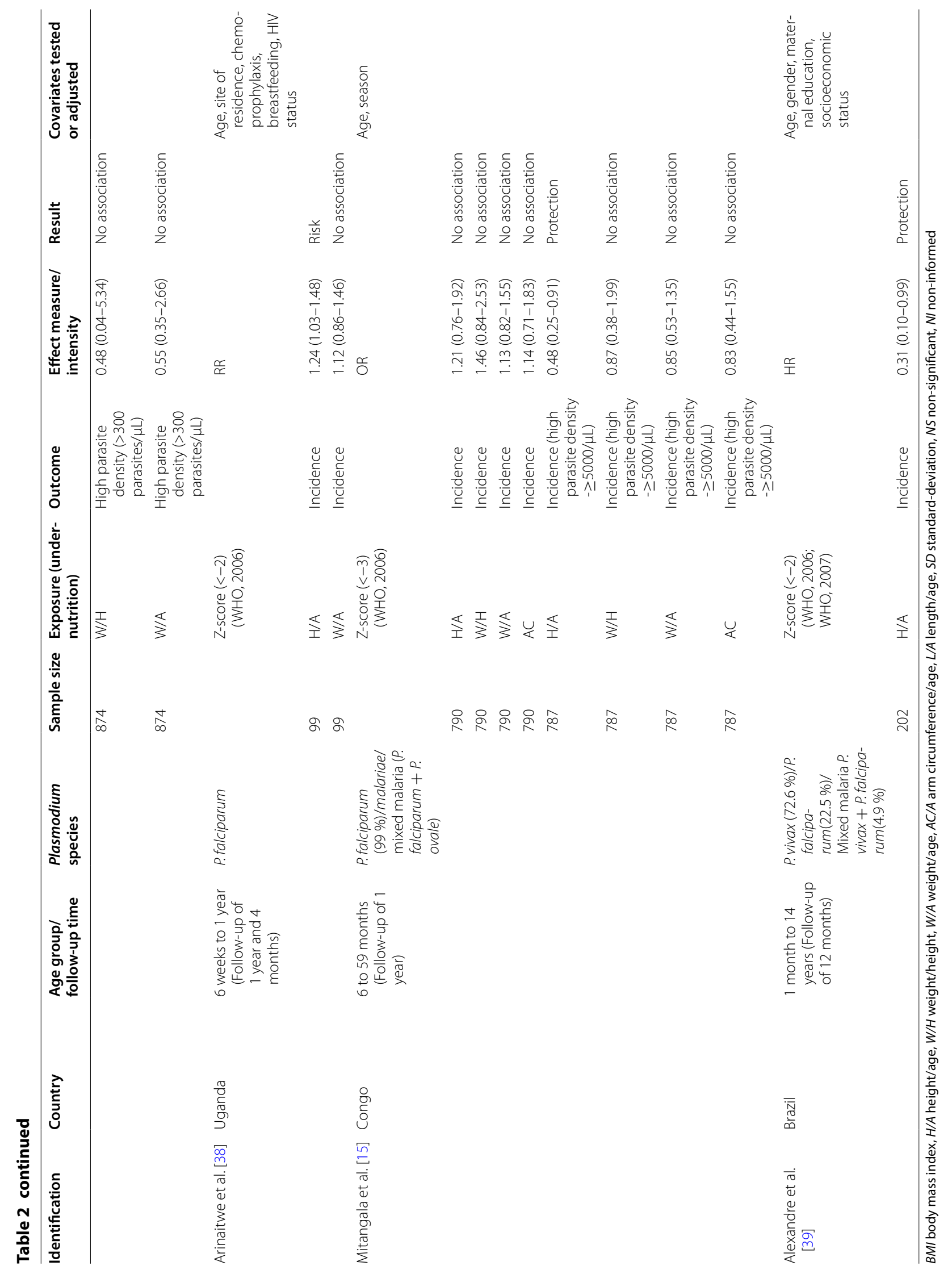




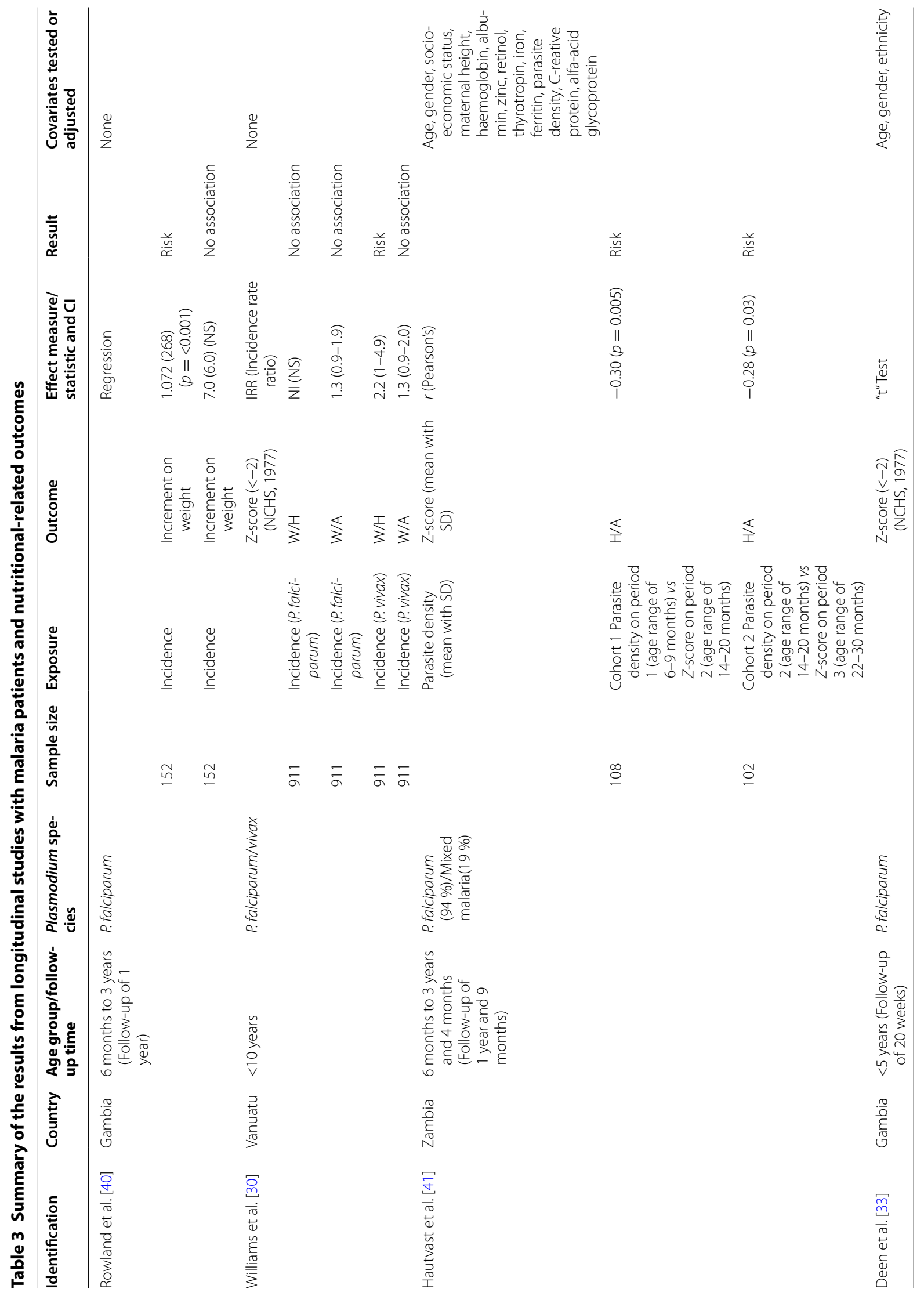




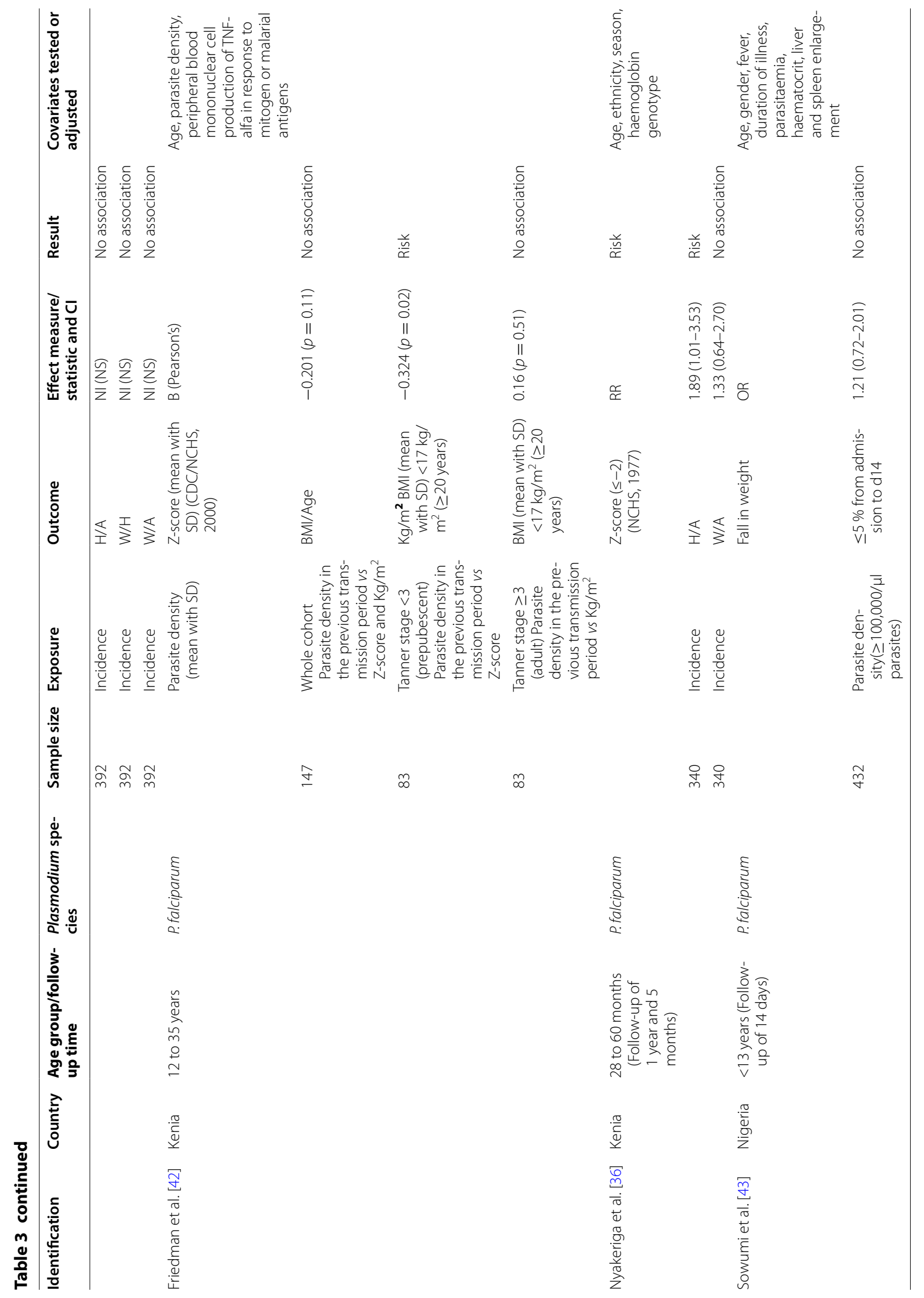




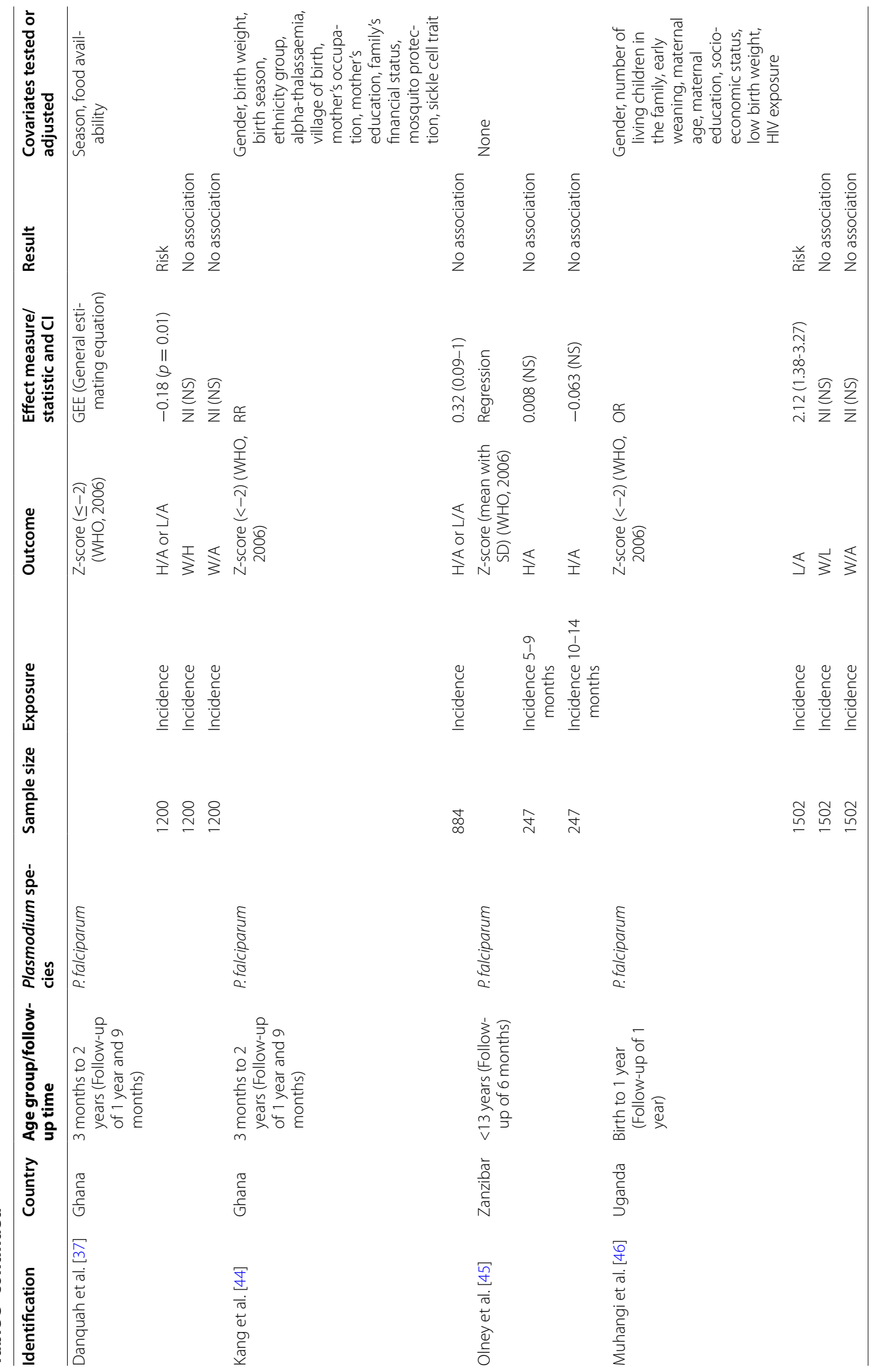




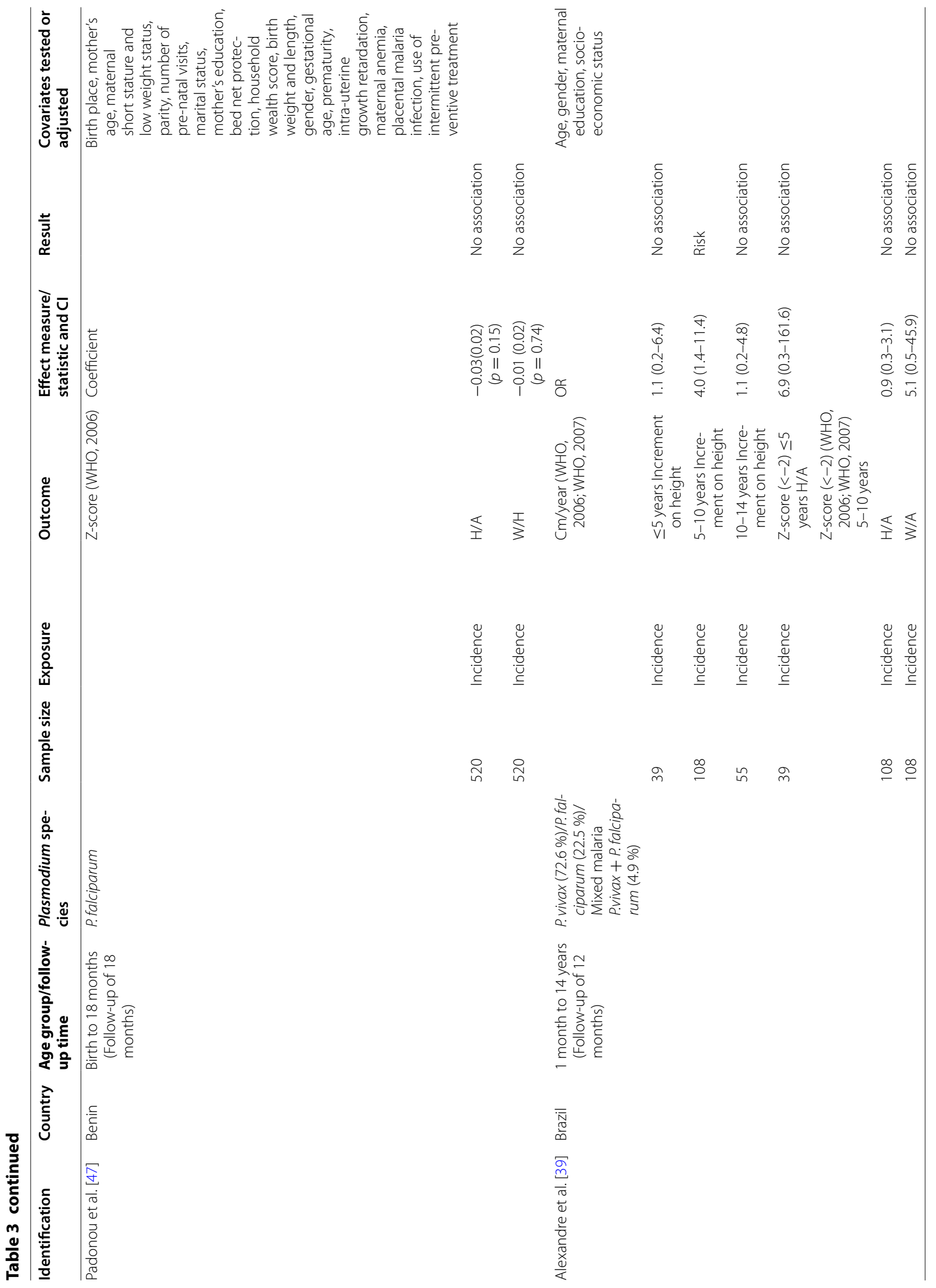




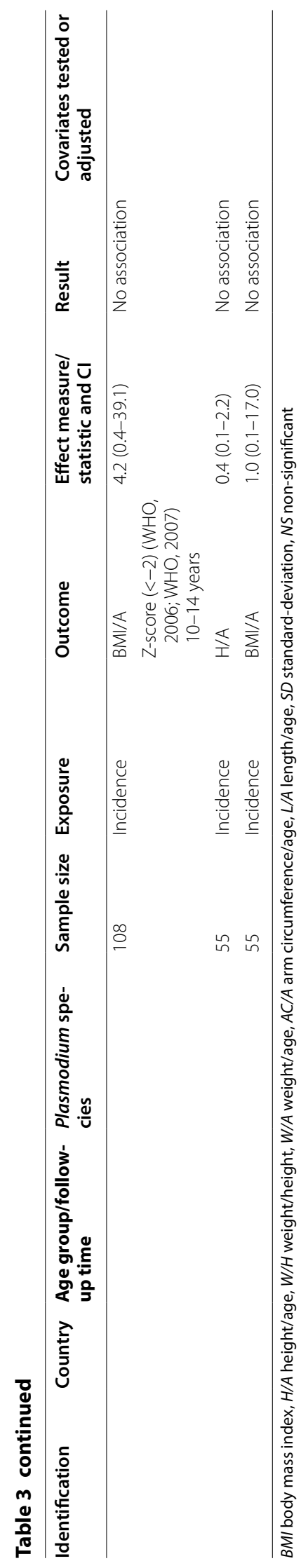




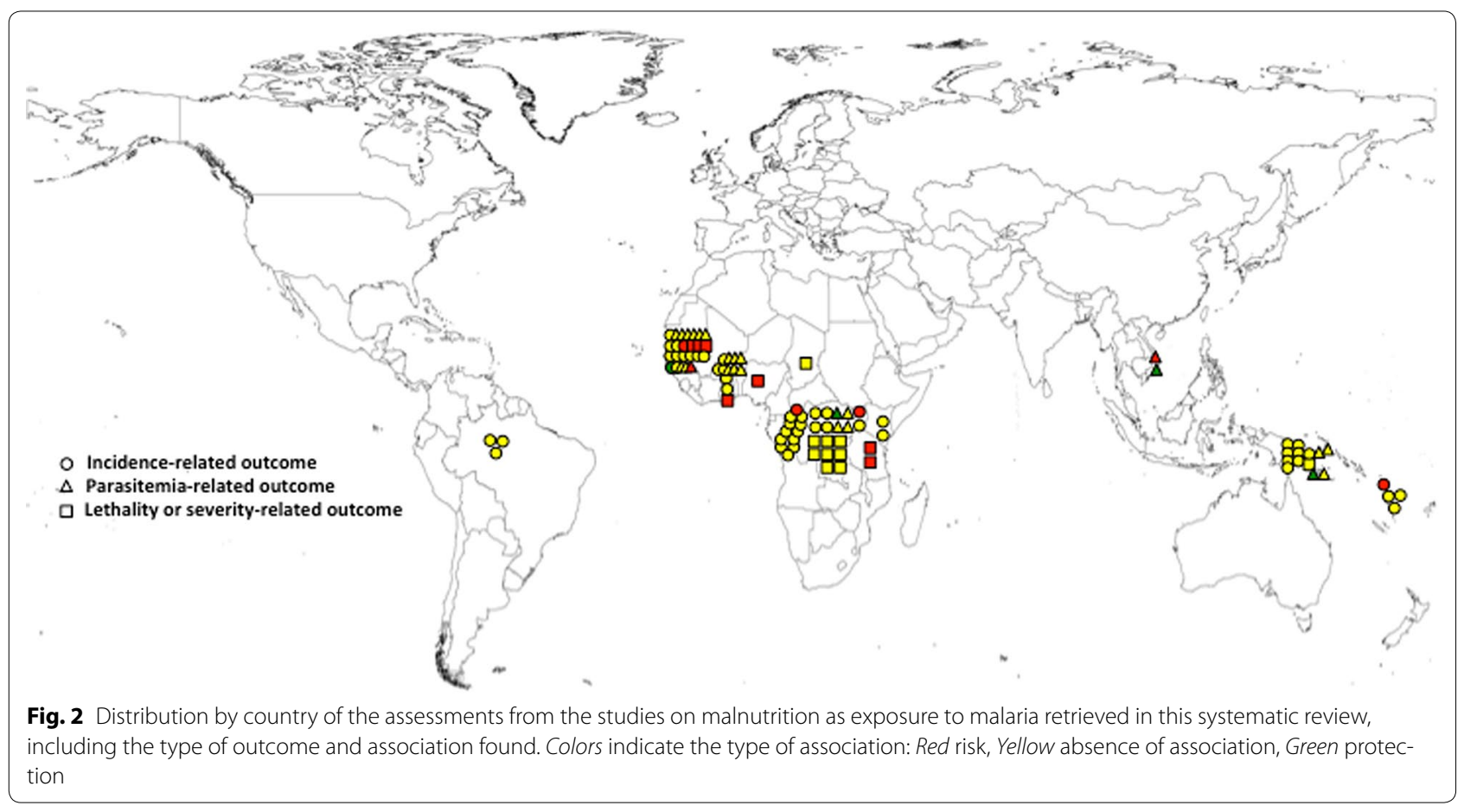

\section{Parasite density}

The 25 assessments of the relationship between malnutrition and malaria parasite density were highly heterogeneous: ten evaluated high parasite density $(\geq 5000$ parasites $/ \mathrm{mL}$ ), three evaluated high parasite density as $\geq 10,000$ parasites $/ \mathrm{mL}$, three evaluated high parasite density as $\geq 5000$ parasites $/ \mathrm{mL}$ in asymptomatic malaria, three evaluated high parasite density as $\geq 300$ parasites/ $\mathrm{mL}$, three evaluated high parasite density as $\geq 5000$ parasites $/ \mathrm{mL}$ specifically in $P$. falciparum malaria, three evaluated high parasite density as $\geq 10,000$ parasites $/ \mathrm{mL}$ specifically in $P$. falciparum malaria, one evaluated time to peak parasitaemia and one evaluated time to peak gametocytaemia.

Although the majority of studies showed no association between malnutrition and parasite density 20/25 (80\%); two evaluations showed a risk association: (1) Weight increments on time to peak $P$. falciparum parasite density in children of undisclosed age and 28 days of follow-up [28]; (2) Stunting on $P$. falciparum parasite density above $300 / \mu \mathrm{L}$ in children above 5 years with 25 weeks of follow-up [17]; while three comparisons showed a protective association: (1) weight increments on time to peak $P$. falciparum gametocytaemia in children of undisclosed age and 28 days of follow-up [28]; (2) Stunting on P. falciparum parasite density of above $5000 / \mu \mathrm{L}$ in children above 5 years with undisclosed follow-up time [16] and (3) Stunting on P. falciparum parasite density of above
$5000 / \mu \mathrm{L}$ in children between 0 and 5 years with 1 year of follow-up [15].

\section{Mortality and severity}

Of the 17 comparisons between malnutrition and mortality, three evaluated malaria, two focused on severe malaria, one in cerebral malaria, and one evaluated three forms: malaria, cerebral and malarial anaemia. There were 10/17 (52.8\%) evaluations with no association between malnutrition and mortality. Seven assessments showed a risk association between malnutrition and mortality in children: (1) underweight on falciparum clinical, cerebral and malarial anaemia in children between 0 and 5 years with undisclosed follow-up time [2]; (2) underweight on falciparum mortality in children 1-7 months and between 8 months and 4 years with 1 year of followup [31]; (3) underweight on falciparum death or recover with neurological deficit on cerebral malaria in children between 1 and 5 years with undisclosed follow-up time [7]; (4) wasting on falciparum severe malaria in children above 5 years with undisclosed follow-up time [35].

\section{Malaria as exposure for malnutrition}

Thirteen studies assessed the impact of malaria in nutrition, of them 10 assessed the role of malaria incidence (yes/no) while the remaining three used parasite density as the exposure of interest. The impact of malnutrition on malaria incidence was measured in 39 assessments 


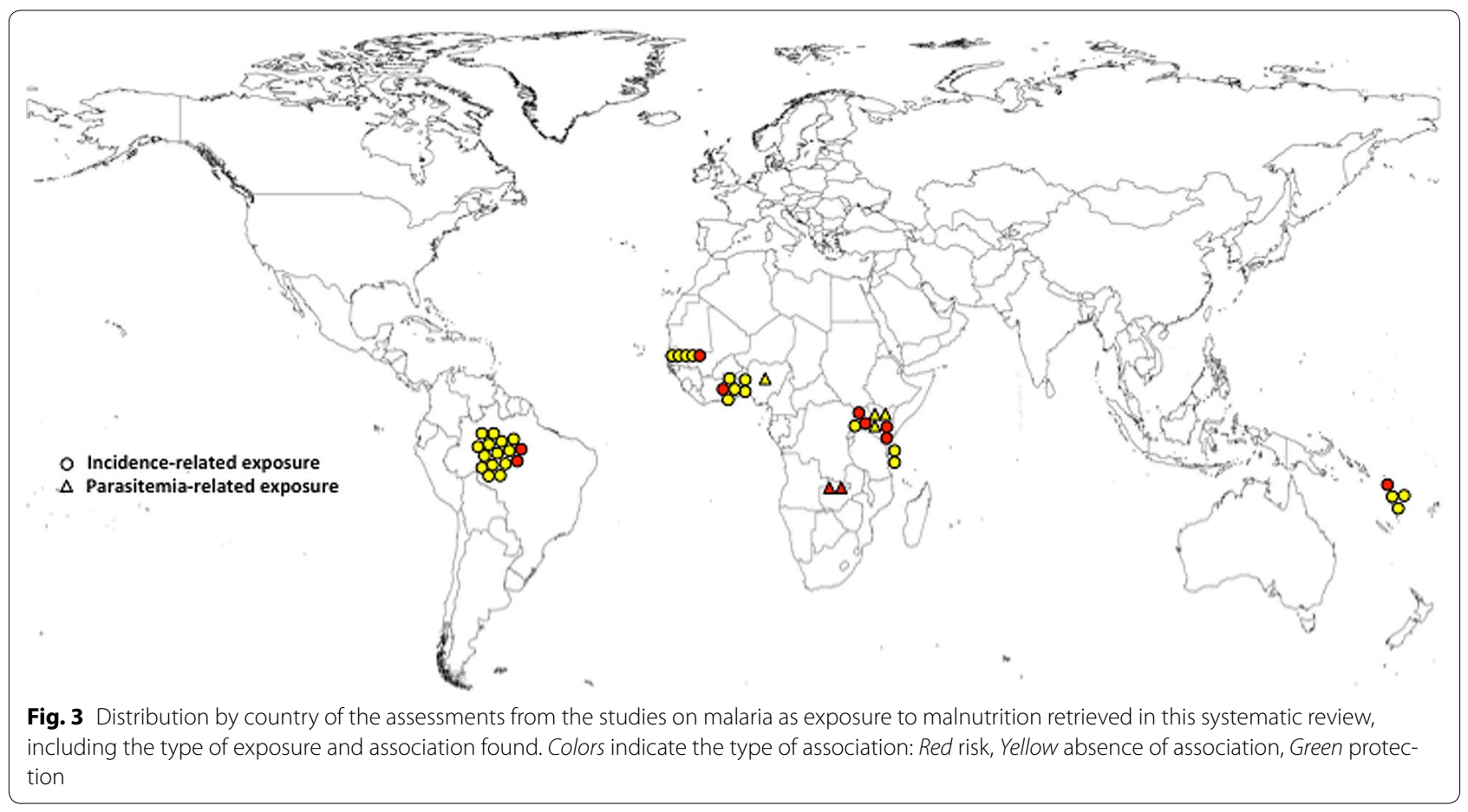

from 10 studies and on parasite density in six assessments from three studies (Table 3; Fig. 3).

\section{Anthropometric parameters}

The most frequently assessed anthropometric measures were $\mathrm{H} / \mathrm{A}$, or $\mathrm{L} / \mathrm{A}$ with 15 evaluations from nine studies, and $\mathrm{W} / \mathrm{H}$ or $\mathrm{W} / \mathrm{L}$ with eight evaluations from six studies. The W/A measure was obtained in seven evaluations from six studies. The measure BMI/A was obtained in five evaluations from two studies and so were height increments. The measure of BMI was evaluated two times in one study and the weight increment and fall in weight were obtained once. Thus, a total of 45 different anthropometric measures were obtained from the 13 studies, being four using NCHS, 1977 [25], five the WHO 2006 [26], one using CDC/NCHS (2000) [48] and one the WHO 2007 [27] as standards. Two studies used weight and/or height change.

Most such evaluations did not show an association between malaria and malnutrition 31/39 (79.4 \%). Eight showed a risk association between malaria and subsequent malnutrition in children: (1) incidence of unspecified malaria on increment in weight in children between 0 and 5 years with 1 year of follow-up [40]; (2) Incidence of vivax malaria on $\mathrm{W} / \mathrm{H}$ in children above 5 years with undisclosed follow-up time [30]; (3) incidence of falciparum malaria on H/A in children between 28 and 60 months with 1 year and 5 months of follow-up [36]; (4) incidence of unspecified malaria on H/A or L/A in children between 3 months to 2 years with 1 year and 9 months of follow-up [37]; (5) incidence of falciparum malaria on L/A and W/A in children from birth to 1 year with 1 year of follow-up [46]; (6) incidence of vivax/ falciparum malaria on increment in height in children $5-10$ years and 0-14 years with 1 year of follow-up [39].

Two out of six $(20 \%)$ assessments showed a positive association between parasite density and malnutrition in children: (1) mean falciparum/mixed malaria parasite density on H/A in children 6-9 months and 14-20 months with 1 year and 9 months of follow-up [41]; (2) mean falciparum parasite density on BMI in children above 5 years with undisclosed follow-up time [42].

\section{Methodological quality of studies}

Of the 20 studies with malarial outcomes, fifteen had high and five had average quality according to the questionnaire of 12 items, with an average score of $80.5 \%$. The main methodological problem in these studies was not describing the main outcome measures (diagnostic technique for malaria and nutritional status). Of the fifteen high-quality studies, eight presented a risk association. Of the five medium quality, one found a risk association, totaling nine studies that found malnutrition as a risk factor for malaria (four in incidence, four mortality, and one in parasite density) (Tables 4, 5).

Of the 13 studies assessing nutritional status as the outcome, eleven had high and two medium quality according to the questionnaire of 12 items, with a mean score 
Table 4 Methodological quality of the longitudinal studies on anthropometric measures as exposures with malariarelated outcomes

\begin{tabular}{|c|c|c|c|c|c|c|c|c|c|c|c|c|c|}
\hline \multirow[t]{2}{*}{ Identification } & \multicolumn{13}{|c|}{ Question } \\
\hline & 1 & 2 & 3 & 4 & 5 & 6 & 7 & 8 & 9 & 10 & 11 & 12 & Score (\%) \\
\hline Pazzaglia et al. [28] & Y & Y & N & Y & N & Y & N & Y & N & N & Y & Y & 58.3 \\
\hline Snow et al. [29] & Y & N & N & Y & Y & N & N & Y & Y & N & - & Y & 54.5 \\
\hline Van den Broeck et al. [21] & Y & $\mathrm{N}$ & $\mathrm{N}$ & N & Y & N & Y & Y & Y & Y & $\mathrm{N}$ & Y & 58.3 \\
\hline Genton et al. [22] & Y & Y & Y & Y & Y & Y & Y & Y & Y & N & - & Y & 90.9 \\
\hline Olumese et al. [7] & Y & Y & $\mathrm{N}$ & Y & Y & Y & N & Y & Y & N & Y & Y & 75.0 \\
\hline Renaudin et al. [20] & Y & $\mathrm{N}$ & Y & Y & $\mathrm{N}$ & N & Y & Y & Y & N & N & Y & 58.3 \\
\hline Williams et al. [30] & Y & Y & Y & Y & Y & N & N & Y & Y & Y & - & Y & 82.8 \\
\hline Man et al. [2] & Y & Y & $\mathrm{N}$ & Y & Y & N & N & Y & Y & N & N & Y & 58.3 \\
\hline Genton et al. [16] & Y & Y & Y & Y & Y & Y & N & Y & Y & Y & Y & Y & 91.6 \\
\hline Schellenberg et al. [31] & Y & Y & Y & Y & Y & $N$ & Y & Y & Y & Y & Y & Y & 91.6 \\
\hline Tonglet et al. [32] & Y & $\mathrm{N}$ & $\mathrm{N}$ & Y & Y & Y & Y & Y & Y & $\mathrm{N}$ & Y & Y & 75.0 \\
\hline Deen et al. [33] & Y & N & Y & Y & Y & Y & Y & Y & Y & Y & Y & Y & 91.6 \\
\hline Müller et al. [34] & Y & Y & Y & Y & Y & Y & N & Y & Y & Y & Y & Y & 91.6 \\
\hline Mockenhaupt et al. [35] & Y & Y & Y & Y & Y & Y & Y & Y & Y & $\mathrm{N}$ & Y & Y & 91.6 \\
\hline Nyakeriga et al. [36] & Y & Y & Y & Y & Y & Y & $\mathrm{N}$ & Y & Y & Y & Y & Y & 91.6 \\
\hline Danquah et al. [37] & Y & N & $\mathrm{N}$ & Y & Y & Y & Y & Y & Y & N & Y & Y & 75.0 \\
\hline Fillol et al. [17] & Y & Y & Y & Y & Y & Y & Y & Y & Y & Y & Y & Y & 100.0 \\
\hline Arinaitwe et al. [38] & Y & N & Y & Y & Y & Y & Y & Y & Y & Y & Y & Y & 91.6 \\
\hline Mitangala et al. [15] & Y & Y & Y & Y & Y & Y & Y & Y & Y & Y & Y & Y & 100.0 \\
\hline Alexandre et al. [39] & Y & Y & Y & Y & $N$ & Y & Y & Y & Y & Y & $N$ & Y & 83.3 \\
\hline
\end{tabular}

(-) not informed

Table 5 Methodological quality of the longitudinal studies with malaria-related exposures and nutritional-related outcomes

\begin{tabular}{|c|c|c|c|c|c|c|c|c|c|c|c|c|c|}
\hline \multirow[t]{2}{*}{ Identification } & \multicolumn{13}{|c|}{ Question } \\
\hline & 1 & 2 & 3 & 4 & 5 & 6 & 7 & 8 & 9 & 10 & 11 & 12 & Score (\%) \\
\hline Rowland et al. [40] & Y & $\mathrm{N}$ & $\mathrm{N}$ & Y & Y & $N$ & $N$ & Y & Y & Y & - & Y & 63.6 \\
\hline Williams et al. [30] & Y & Y & Y & Y & Y & $\mathrm{N}$ & $\mathrm{N}$ & Y & Y & Y & - & Y & 81.8 \\
\hline Hautvast et al. [41] & Y & Y & Y & Y & Y & Y & Y & Y & Y & Y & Y & Y & 100.0 \\
\hline Deen et al. [33] & Y & $\mathrm{N}$ & Y & Y & Y & Y & Y & Y & Y & Y & Y & Y & 91.6 \\
\hline Friedman et al. [42] & Y & $\mathrm{N}$ & Y & Y & Y & Y & Y & Y & Y & Y & Y & Y & 91.6 \\
\hline Nyakeriga et al. [36] & Y & Y & Y & Y & Y & Y & $N$ & Y & Y & Y & Y & Y & 91.6 \\
\hline Sowumi et al. [43] & Y & Y & Y & Y & Y & Y & $N$ & Y & Y & Y & Y & Y & 91.6 \\
\hline Danquah et al. [37] & Y & $\mathrm{N}$ & $N$ & Y & Y & Y & Y & Y & Y & $N$ & Y & Y & 75.0 \\
\hline Kang et al. [44] & Y & $\mathrm{N}$ & Y & Y & Y & $\mathrm{N}$ & $\mathrm{N}$ & Y & Y & Y & Y & Y & 75.0 \\
\hline Olney et al. [45] & Y & $\mathrm{N}$ & $N$ & Y & $\mathrm{N}$ & $N$ & Y & Y & Y & Y & Y & Y & 66.6 \\
\hline Muhangi et al. [46] & Y & Y & Y & Y & Y & Y & Y & Y & Y & Y & - & Y & 90.9 \\
\hline Padonou et al. [47] & Y & Y & Y & Y & Y & Y & Y & Y & Y & Y & Y & Y & 100.0 \\
\hline Alexandre et al. [39] & Y & Y & Y & Y & $N$ & Y & Y & Y & Y & Y & $\mathrm{N}$ & Y & 83.3 \\
\hline
\end{tabular}

(-) not informed

of $84.8 \%$. The main methodological problem in these studies was not clearly describing the exposure and the outcome (malaria species or anthropometric indicators with their anthropometric references). Of the eleven high quality studies, six had positive associations. Of the two medium quality, one found a positive association, totaling seven studies that found malaria as risk factor for malnutrition ( 5 using malaria incidence and 2 using parasite density). 


\section{Discussion}

Previous studies on the association of malaria and malnutrition delivered inconsistent results. These conflicting results could be explained by different levels of confounding and to considerable methodological dissimilarities. Randomized controlled trials are impractical and previous observational studies have not fully controlled for potential confounding including nutritional deficiencies, breastfeeding habits, other infectious diseases and socioeconomic status [46]. For the purpose of this systematic review, we restricted the nutritional assessment metrics to the above listed anthropometric measures as these have shown to be strong, reproducible indicators [49]. A significant heterogeneity in the assessed studies was observed in terms of sample size, follow-up time, exposure and outcome definitions, thus impeding a metanalysis, but in general the methodological quality of the retrieved studies was good enough to generate important conclusions. Here, results from longitudinal studies were emphasized, thus allowing temporal definitions, but quality of anthropometric measurements and their comparability across studies may constitute limitations.

The majority of studies showed no association between malnutrition and subsequent malaria incidence or parasite density. One study suggested a protective effect against malaria for malnutrition diagnosed by W/A [17]. In contrast, other studies have found an increased risk of malaria among stunted and underweight children [30, 32, 33, 38]. Earlier studies showed the presence of malaria in famine victims within few days of re-feeding and suggested that feeding provided essential nutrients for sequestered parasites leading to recrudescent infection $[50,51]$. Whether other nutritional parameters are involved in the pathophysiology of nutrition and malaria is still controversial. The role of vitamin A, iron, zinc and other micronutrients in malaria is still a topic of debate [52]. In monkeys and mice, a low-protein diet was associated to a lower parasitaemia [53-55]. Most works found greater effects in younger age groups $[17,32,36]$.

Measuring the association between measures of malnutrition and the risk of malaria is complex and is hampered by the multiplicity of metrics used for malnutrition. Stunting is generally considered an indicator of chronic malnutrition, wasting generally reflects a more recent and severe process, and being underweight is likely the result of both factors [38]. The results presented in this review support that malnutrition has not a great impact on malaria incidence and parasitaemia, although in a few epidemiological scenarios stunting, underweight and decreased increment on weight over time were measures of chronic malnutrition associated with an increased risk of malaria or high parasite density. Children who are underweight likely have increased susceptibility to malaria, most notably through a reduction in the function of the immune system [56]. An undernourished child is unable to mount an appropriate immune response to the malaria parasite due to reduction in $\mathrm{T}$ lymphocytes, impairment of antibody formation, decreased complement formation and atrophy of lymphoid tissues $[1,17]$. Monkeys maintained on a lowprotein diet were unable to clear the infection, resulting in multiple recrudescences [53]. Immune responses were also suppressed and parasitaemia appeared earlier and lasted longer in non-human primates [57].

The impact of malnutrition was noted mostly in malaria mortality and severity. Death or recovery with a neurological deficit on cerebral malaria was significantly associated with malnutrition in Nigerian children [7]. Underweight was identified as a risk factor for mortality, cerebral malaria and malarial anaemia in Gambian children [2] and with mortality in Tanzanian children, mostly in younger age groups [31]. Wasting was associated to mortality in children above 5 years in Ghana [35]. Some series of cases showed that cerebral malaria was more prevalent in well-nourished children than in children with severe malnutrition including kwashiorkor or marasmus [12, 13, 58]. In this study, cohort studies that evaluated mortality and other adverse malaria outcomes show risk of severe malnutrition [2, 7, 31, 35]. As shown previously, anthropometric measurements are consistently related to the risk of outcomes such as mortality in community-based studies from Asia and Africa [59]. In mice, it was noted an increased lethality in severely malnourished animals [60]. Although information on sensitive treatment surveillance was generally absent in the studies, it use some locations would be biased toward detecting differences in the onset of a malaria episode and not necessarily the subsequent severity. In malnutrition as exposure to malaria morbidity, studies that found protective associations had at least 1 year of follow-up whereas studies with risk associations only followed for 6 months or less. Most of the associations were found for height/age index, a marker of stunting or chronic malnutrition.

Anthropometric interaction of malaria and nutrition is confounded by micronutrient status, which also impacts on malaria severity [61], but unfortunately this potential bias was approached only in one study. The inability of anthopometry to distinguish the effect of specific nutrient deficiencies that affect growth in children is another limitation of this method [62]. Only five studies controlled for malaria treatment exposure [17, 22, 38, 44, 47] and four controlled for vector control measures $[15,16$, $34,47]$. Prevention of malaria by intermittent preventive treatment was found to improve weight status in children [42, 63]. If malaria-specific interventions are responsible 
for this accelerated linear growth rate, the most likely explanation is that early treatment of clinical malaria prevented prolonged carriage of $P$. falciparum and its associated growth-depressing immune response [63]. Thus, a bias can be present in studies without this control. Different anthropometric assessment methods from studies with small sample sizes limited the comparability between findings retrieved in this study. It is known that WHO standards provide a better tool to monitor the rapid and changing rate of growth in early infancy [64]. Results from the retrieved studies were controlled for socioeconomic factors in a few cases, increasing the possibility of confounding [49].

Plasmodium vivax infection has been associated with severe malaria and death [65], although the risk of severe vivax malaria and case fatality rates are not well defined [66]. Co-morbidities are considered important contributors to severe complications of $P$. vivax infection. In particular, concomitant malnutrition is suspected to increase the risk of severe vivax disease, but this is not well understood. The demographic risk of severe vivax malaria in regions of relatively high endemicity is skewed towards early infancy (a stage when severe anaemia is a major cause of morbidity). A clearer picture of severe vivax malaria is emerging, but further studies are required to refine existing knowledge of the spectrum of syndromes and its association with malnutrition [39].

The relative insensitivity of anthropometry to detect changes in nutritional status over short periods of time limited conclusions from studies of short follow-ups. One speculates that hypercatabolism and inflammatory status induced by malaria may have an effect on nutritional well-being. TNF is a known mediator of anorexia and cachexia seen in many human disease states and is elevated during acute malaria [67-69]. In this systematic review, most of the studies showed no association between malaria incidence and malnutrition. As most anthropometric measures used gauged chronic malnutrition, one could speculate that if malaria has an effect on nutritional status, it would have be assessed with metrics targeting acute malnutrition. In areas where malaria is hyper-endemic, repeated infections throughout life may contribute to the burden of malnutrition, specially in children [36, 37, 40,46]. No risk associations were found for malaria as exposure to malnutrition in studies with less than 1 year of follow-up.

Interestingly, in Vanuatu and in the Brazilian Amazon, where $P$. vivax contributes with a great percentage of the malaria cases, malaria has been associated with malnutrition in children [30, 39]. In these areas there is a general consensus stating that $P$. vivax would not be associated with malnutrition due to the misleading information that vivax malaria is benign [66]. However, this parasite species is able to develop dormant stages (hypnozoites) in the liver leading to frequent relapses, even months after the primary infection [70]. One especulates that this chronic relapsing nature of $P$. vivax may lead to a degree of chronic inflammation. Whether relapsing malaria significantly impairs nutritional status in $P$. vivax affected areas warrants further research.

\section{Conclusion}

In conclusion, this systematic review found that the majority of studies assessing malaria and malnutrition were carried out in African P. falciparum endemic areas, with a significant study heterogeneity in terms of sample size, follow-up time and exposure and outcome definitions. Considering malnutrition as exposure, the results presented in this review support that malnutrition has not a great impact on malaria incidence and parasitaemia, but a greater negative impact of malnutrition was noted in malaria mortality and severity. A scarcity of prospective studies have been carried out aiming to establish the relationship between nutritional status and severity of vivax infection, this being a prioritary research topic. Most of the assessed studies showed no association between malaria incidence and malnutrition in areas of $P$. falciparum predominance, although the anthropometric parameters used were aimed mostly at chronic malnutrition, possibly suggesting that the impact of malaria on nutritional status may be of little significance in the long term. Interestingly, in areas where $P$. vivax contributes with a great percentage of the cases, malaria was associated with risk for malnutrition in children. A discussion among experts in the field is needed to standardize the observational studies considering external validity in order to allow for more accurate conclusions.

\section{Authors' contributions}

AMS, MAA, MVGL and WMM conceived the study. AMS, MAA and WMM designed the methods. EFA, MAA, SGB, JLS and WMM conducted the analysis and wrote the manuscript. All authors read and approved the final manuscript.

\section{Author details}

${ }^{1}$ Fundação de Medicina Tropical Dr. Heitor Vieira Dourado, Av. Pedro Teixeira, 25, Dom Pedro, Manaus, AM 69040-000, Brazil. ${ }^{2}$ Universidade do Estado do Amazonas, Av. Pedro Teixeira, 25, Dom Pedro, Manaus, AM 69040-000, Brazil.

3 Division of Infectious Diseases, Department of Medicine, School of Medicine, Emory University, 49 Jesse Hill Jr Drive, Atlanta, GA 30303, USA. ${ }^{4}$ Instituto Nacional de Infectologia Evandro Chagas, Fundação Oswaldo Cruz, Av. Brasil, 4365, Manguinhos, Rio de Janeiro, RJ 21040-360, Brazil. ${ }^{5}$ Instituto de Pesquisas Leônidas and Maria Deane, Fundação Oswaldo Cruz, Rua Terezina, 476, Adrianópolis, Manaus, AM 69057-070, Brazil.

\section{Acknowledgements}

We would like to thank the research community for inspiration and contribution of the material for this systematic review. This study was supported by the Brazilian Council for Scientific and Technological Development (CNPq) (PRONEX Malaria; Grant number 575788/2008-9) and the Amazonas Research Support Foundation (FAPEAM) (HEMOVIVAX; Grant numbers 1027/2011 and 3140/2012). JLS participation was supported by NIH Research Training Grant \# R25 TW009337 funded by the Fogarty International Center. MVGL is a level 1 
fellowship from the National Council for Scientific and Technological Development (CNPq).

\section{Compliance with ethical guidelines}

\section{Competing interests}

The authors declare that they have no competing interests. The funders had no role in the study design, data collection, analysis, decision to publish, or preparation of the manuscript.

Received: 10 June 2015 Accepted: 25 August 2015

Published online: 17 September 2015

\section{References}

1. Scrimshaw NS, SanGiovanni JP. Synergism of nutrition, infection, and immunity: an overview. Am J Clin Nutr. 1997;66:464S-77S.

2. Man WD, Weber M, Palmer A, Schneider G, Wadda R, Jaffar S, et al. Nutritional status of children admitted to hospital with different diseases and its relationship to outcome in The Gambia, West Africa. Trop Med Int Health. 1998;3:678-86.

3. Raiten DJ, Sakr Ashour FA, Ross AC, Meydani SN, Dawson HD, et al. Inflammation and nutritional science for programs/policies and interpretation of research evidence (INSPIRE). J Nutr. 2015;145:1039S-108S.

4. WHO. World Malaria Report 2013. World Health Organization, Geneva. 2013. http://www.who.int/malaria/publications/world_malaria_ report_2013/en/. Accessed 12 Nov 2014.

5. UNICEF. Progress for children: a World fit for children: statistical review. New York: United Nations; 2007. p. 19-24.

6. Rice AL, Sacco L, Hyder A, Black RE. Malnutrition as an underlying cause of childhood deaths associated with infectious diseases in developing countries. Bull World Health Organ. 2000;78:1207-21.

7. Olumese PE, Sodeinde O, Ademowo OG, Walker O. Protein energy malnutrition and cerebral malaria in Nigerian children. J Trop Pediatr. 1997;43:217-9.

8. Imbert P, Sartelet I, Rogier C, Ka S, Baujat G, Candito D. Severe malaria among children in a low seasonal transmission area, Dakar, Senegal: influence of age on clinical presentation. Trans R Soc Trop Med Hyg. 1997;91:22-4.

9. Nacher M, Singhasivanon P, Vannaphan S, Treeprasertsuk S, Phanumaphorn M, Traore B, et al. Socio-economic and environmental protective/ risk factors for severe malaria in Thailand. Acta Trop. 2001;78:139-46.

10. Nacher M, Singhasivanon P, Treeprasertsuk S, Vannaphan S, Traore B, Looareesuwan $\mathrm{S}$, et al. Intestinal helminths and malnutrition are independently associated with protection from cerebral malaria in Thailand. Ann Trop Med Parasitol. 2002;96:5-13.

11. Ahmad SH, Moonis R, Shahab T, Khan HM, Jilani T. Effect of nutritional status on total parasite count. Ind J Pediatr. 1985;52:285-8.

12. Goyal SC. Protein energy malnutrition and cerebral malaria. J Trop Pediatr. 1991:37:141-4.

13. Hendrickse RG, Hasan AH, Olumide LO, Akinkunmi A. An investigation of five hundred seriously ill children in whom a "clinical" diagnosis of malaria was made on admisssion to the Children's Emergency Room at University College Hospital, Ibadan. Ann Trop Med Parasitol. 1971;65:1-20.

14. Thuma PE, van Dijk J, Bucala R, Debebe Z, Nekhai S, Kuddo T, et al. Distinct clinical and immunologic profiles in severe malarial anemia and cerebral malaria in Zambia. J Infect Dis. 2011;203:211-9.

15. Mitangala PN, D'Alessandro U, Donnen P, Hennart P, Porignon D, Bisimwa Balaluka G, et al. Infection palustre et état nutritionnel: résultats d'une cohorte d'enfant âges de 6 à 59 mois au Kivu en République démocratique du Congo. Rev Epidemiol Santé Publique. 2013;61:111-20.

16. Genton B, Al-Yaman F, Ginny M, Taraika J, Alpers MP. Relation of anthropometry to malaria morbidity and immunity in Papua New Guinean children. Am J Clin Nutr. 1998;68:734-41.

17. Fillol F, Cournil A, Boulanger D, Cissé B, Sokhna C, Targett G, et al. Influence of wasting and stunting at the onset of the rainy season on subsequent malaria morbidity among rural preschool children in Senegal. Am J Trop Med Hyg. 2009;80:202-8.
18. Faye O, Correa J, Camara B, Dieng T, Dieng Y, Gaye O, et al. Malaria letality in pediatric unit of Dakar hospital: study of risk factors. Méd Trop. 1998;58:361-4.

19. Razanamparany MS, Randriamiharisoa FA, Razanamparany NJ, Ramialimanana V. L'épidémie de paludisme à Antananarivo de 1983 à 1994 vue à travers le service de Pédiatrie A de l'Hôpital général de Befelatanana. Cahiers Santé. 1995;5:382-5.

20. Renaudin P. Evaluation de l'etat nutritionnel de l'enfant de moins de 5 ans a Moundou, Tchad: relations avec la morbidite et la mortalite hospitalieres. Med Trop (Mars). 1997;57:49-54.

21. Van Den Broeck J, Eeckels R, Vuylsteke J. Influence of nutritional status on child mortality in rural Zaire. Lancet. 1993;341:1491-5.

22. Genton B, Al-Yaman F, Alpers MP, Mokela D. Indicators of fatal outcome in paediatric cerebral malaria: a study of 134 comatose papua new guinean children. Int J Epidemiol. 1997;26:670-6.

23. World Health Organization. Severe falciparum malaria. Trans R Soc Trop Med Hyg. 2000;94:S1-90.

24. Downs S, Black N. The feasibility of creating a checklist for the assessment of the methodological quality both of randomised and non-randomised studies of health care interventions. J Epidemiol Community Health. 1998;52:377-84.

25. National Center for Health Statistics. NCHS Growth curves for children, birth-18 years. United States: Vital and Health Statistics; 1977. p. 1-74.

26. WHO Multicentre Growth Reference Study Group. WHO Child Growth Standards: length/height-for-age, weight-for-age, weight-for-length weight-for-height and body mass index-for-age: methods and development. Geneva: World Health Organization; 2006 (Accessed 15 Aug 2015).

27. Onis M, Onyango AW, Borghi E, Siyam A, Nishida C, Siekmann J. Development of a WHO growth reference for school-aged children and adolescents. Bull World Health Organ. 2007;85:660-7.

28. Pazzaglia G, Woodward WE. An analysis of the relationship of host factors to clinical falciparum malaria by multiple regression techniques. Am J Trop Med Hyg. 1982;31:202-10.

29. Snow RW, Byass P, Shenton FC, Greenwood BM. The relationship between anthropometric measurements and measurements of iron status and susceptibility to malaria in Gambian children. Trans R Soc Trop Med Hyg. 1991;85:584-9.

30. Williams TN, Maitland K, Phelps L, Bennett S, Peto TE, Viji J, et al. Plasmodium vivax: a cause of malnutrition in young children. Q J Med. 1997;90:751-7.

31. Schellenberg D, Menendez C, Kahigwa E, Font F, Galindo C, Acosta C, et al. African children with malaria in an area of intense Plasmodium falciparum transmission: features on admission to the hospital and risk factors for death. Am J Trop Med Hyg. 1999;61:431-8.

32. Tonglet R, Mahangaiko Lembo E, Zihindula PM, Wodon A, Dramaix M, et al. How useful are anthropometric, clinical and dietary measurements of nutritional status as predictors of morbidity of young children in central Africa? Trop Geogr Med. 1999:4:120-30.

33. Deen $J L$, Walraven GEL, von Seidlen L. Increased risk for malaria in chronically malnourished children under 5 years of age in rural Gambia. J Trop Pediatr. 2002:48:78-83.

34. Müller $\mathrm{O}$, Garenne M, Kouyaté B, Becher H. The association between protein-energy malnutrition, malaria morbidity and all-cause mortality in west african children. Trop Med Int Health. 2003;8:507-11.

35. Mockenhaupt FP, Ehrhardt S, Burkhardt J, Bosomtwe SY, Laryea S, Anemana SD, et al. Manifestation and outcome of severe malaria in children in northern Ghana. Am J Trop Med Hyg. 2004;71:167-72.

36. Nyakeriga AM, Troye-Blomberg M, Chemtai AK, Marsh K, Williams TN. Malaria and nutritional status in children living on the coast of Kenya. Am J Clin Nutr. 2004;80:1604-10.

37. Danquah I, Dietz E, Zanger P, Reither K, Ziniel P, Bienzle U, et al. Reduced efficacy of intermittent preventive treatment of malaria in malnourished children. Antimicrob Agents Chemother. 2009:53:1753-9.

38. Arinaitwe E, Gasasira A, Verret W, Homsy J, Wanzira H, Kakuru A, et al. The association between malnutrition and the incidence of malaria among young HIV-infected and -uninfected Ugandan children: a prospective study. Malar J. 2012;11:90.

39. Alexandre MAA, Benzecry SG, Siqueira AM, Vitor-Silva S, Melo GC, Monteiro WM, et al. The association between nutritional status and malaria in 
children from a rural community in the Amazonian Region: a longitudinal study. PLoS Negl Trop Dis. 2015;9:e0003743.

40. Rowland MG, Cole TJ, Whitehead GG. A quantitative study into the role of infection in determining nutritional status in Gambian village children. $\mathrm{Br}$ J Nutr. 1977;37:441-50.

41. Hautvast JL, Tolboom JJ, Kafwembe EM, Musonda RM, Mwanakasale $V$, van Staveren WA, et al. Severe linear growth retardation in rural Zambian children: the influence of biological variables. Am J Clin Nutr. 2000;71:550-9.

42. Friedman JF, Kurtis JD, Mtalib R, Opollo M, Lanar DE, Duffy PE. Malaria is related to decreased nutritional status among male adolescents and adults in the setting of intense perennial transmission. J Infect Dis. 2003;188:449-57.

43. Sowunmi A, Gbotosho GO, Adedeji AA, Fateye BA, Sabitu MF, Happi CT, et al. Effects of acute Plasmodium falciparum malaria on body weight in children in an endemic area. Parasitol Res. 2007;101:343-9.

44. Kang H, Kreuels B, Adjei O, Krumkamp R, May J, Small DS. The causal effect of malaria on stunting: a Mendelian randomization and matching approach. Int J Epidemiol. 2013;42:1390-8.

45. Olney DK, Kariger PK, Stoltzfus RJ, Khalfan SS, Ali NS, Tielsch JM, et al. Developmental effects of micronutrient supplementation and malaria in zanzibari children. Early Hum Dev. 2013;89:667-74.

46. Muhangi L, Lule SA, Mpairwe H, Ndibazza J, Kizza M, Nampijja M, et al. Maternal HIV infection and others factors associated with growth outcomes of HIV-uninfected infants in Entebbe, Uganda. Publ Health Nutr. 2013;16:1548-57.

47. Padonou G, Le Port A, Cottrell G, Guerra J, Choudat I, Rachas A, et al. Factors associated with growth patterns from birth to 18 months in a Beninese cohort of children. Acta Trop. 2014;135:1-9.

48. Centers for Disease Control and Prevention. National Center for Health Statistics. CDC growth charts: United States. Hyaltsville: CDC; 2000. p. 2002.

49. Pelletier DL, Low JW, Johnson FC, Msukwa LA. Child anthropometry and mortality in Malawi: testing for effect modification by age and length of follow-up and confounding by socioeconomic factors. J Nutr. 1994;124:2082S-105S.

50. Murray MJ, Murray NJ, Murray AB, Murray MB. Refeeding-malaria and hyperferraemia. Lancet. 1975;1:653-4.

51. Murray MJ, Murray AB, Murray MB, Murray CJ. Somali food shelters in the Ogaden famine and their impact on health. Lancet. 1976;1:1283-5.

52. Shankar AH. Nutritional modulation of malaria morbidity and mortality. J Infect Dis. 2000;182:37-53.

53. Ray AP. Haematological studies on Simian malaria. II. Blood picture in monkeys during acute and chronic stages of P. knowlesi infection. Indian J Malariol. 1957:4:360

54. Platt BS, Dema IS, Miller DS. Effect of protein values of the diet on the course of malarial infection (Plasmodium berghei) in rats. Proc Nutr Soc. 1960;19:xi.

55. Ramakrishnan SP. Studies on Plasmodium berghei, Vincke and Lips, 1948. XVII. Effect of different quantities of the same diet on the course of blood-induced infection in rats. Indian J Malariol. 1954;8:89-96.
56. Caulfield LE, de Onis M, Blössner M, Black RE. Undernutrition as an underlying cause of child deaths associated with diarrhea, pneumonia, malaria, and measles. Am J Clin Nutr. 2004;80:193-8.

57. Bazaz-Malik G, Tatke M. Response to Plasmodium cynomolgi infection in a protein deficient host. Indian J Med Res. 1982;76:527-33.

58. Edington GM. Cerebral malaria in the Gold Coast African: four autopsy reports. Ann Trop Med Parasitol. 1954;48:300-6.

59. Pelletier DL. The relationship between child anthropometry and mortality in developing countries: implications for policy, programs and future research. J Nutr. 1994;124:2047S-81S.

60. Fagbenro-Beyioku AF, Oyerinde JPO. Effect of host-diet inadequacy on the course of infection of Plasmodium yoelii nigeriensis. West Afr J Med. 1990:9:124-8.

61. Mfonkeu JB, Gouado I, Kuaté HF, Zambou O, Combes V, Grau GE, et al. Biochemical markers of nutritional status and childhood malaria severity in Cameroon. Br J Nutr. 2010;104:886-92.

62. Shetty P. Measures of nutritional status from anthropometic survey data. Food and Agriculture Organization of the United Nations: measurement and assessment of food deprivation and undernutrition; 2003. pp 427.

63. Ntab B, Cissé B, Boulanger D, Sokhna C, Targett G, Lines J, et al. Impact of intermittent preventive anti-malarial treatment on the growth and nutritional status of preschool children in rural Senegal (West Africa). Am J Trop Med Hyg. 2007;77:411-7.

64. de Onis M, Onyango AW, Borghi E, Garza C, Yang H, WHO Multicentre Growth Reference Study Group. Comparison of the World Health Organization (WHO) child growth standards and the National Center for Health Statistics/WHO international growth reference: implications for child health programmes. Public Health Nutr. 2006;9:942-7.

65. Lacerda MV, Fragoso SC, Alecrim MG, Alexandre MA, Magalhães BM, Siqueira AM, et al. Postmortem characterization of patients with clinical diagnosis of Plasmodium vivax malaria: to what extent does this parasite kill? Clin Infect Dis. 2012;55:67-74.

66. Anstey N, Douglas MD, Poespoprodjo JR, Price RN. Plasmodium vivax: clinical spectrum, risk factors and pathogenesis. Adv Parasitol. 2012;80:151-201.

67. Tracey KJ, Cerami A. Tumor necrosis factor in the malnutrition (cachexia) of infection and cancer. Am J Trop Med Hyg. 1992;47:2-7.

68. Arnalich F, Martinez P, Hernanz A, González J, Plaza MA, Montiel C, et al. Altered concentrations of appetite regulators may contribute to the development and maintenance of HIV-associated wasting. AIDS. 1997;11:1129-34.

69. Kotler DP. Cachexia. Ann Intern Med. 2000;133:622-34.

70. Mueller I, Galinski MR, Baird JK, Carlton JM, Kochar DK, Alonso PL, et al. Key gaps in the knowledge of Plasmodium vivax, a neglected human malaria parasite. Lancet Infect Dis. 2009;9:555-66.

\section{Submit your next manuscript to BioMed Central and take full advantage of:}

- Convenient online submission

- Thorough peer review

- No space constraints or color figure charges

- Immediate publication on acceptance

- Inclusion in PubMed, CAS, Scopus and Google Scholar

- Research which is freely available for redistribution

Submit your manuscript at 